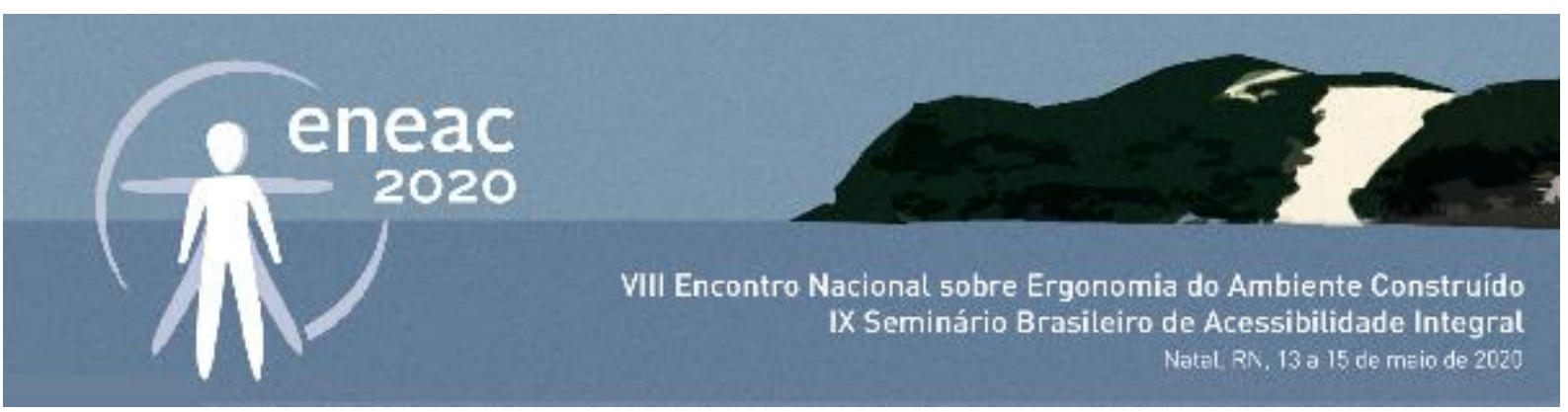

\title{
Design, Ergonomia, Tecnologia Assistiva e Acessibilidade: Pesquisa e Desenvolvimento para a Integração Social de Pessoas com Capacidades Específicas (PCE)
}

\author{
Design, Ergonomics, Assistive Technology and Accessibility: Research and \\ Development for the Social Integration of People with Specific \\ Capabilities (PSC)
}

LUIS CARLOS PASCHOARELLI

Professor Titular, PPGDesign-UNESP, luis.paschoarelli@unesp.br

\begin{abstract}
RESUMO
As novas tecnologias tem impactado o modo de vida de toda sociedade, mas aquelas Pessoas com Capacidades Específicas (PCE) apresentam particularidades em que os problemas de acessibilidade e usabilidade se acentuam. São PCE's as pessoas com deficiência (PCD) permanente ou temporária, os idosos, as crianças e outros integrantes considerados minoritários. O Processo de Desenvolvimento de Produto (PDP) tem que considerar, de modo amplo e irrestrito, as demandas específicas das características físicas, biológicas e cognitivas desses grupos, bem como os aspectos práticos de uso, estéticos e sociais (para além dos antropológicos, tecnológicos, econômicos e ecológicos), os quais têm papel fundamental no acesso e integração social desses indivíduos. O objetivo será apresentar brevemente os conceitos de Design, Ergonomia, TA e Acessibilidade; e como os conhecimentos dessas áreas podem atuar integralmente no PDP de artefatos para PCE's. Serão apresentados e discutidos exemplos de estudos aplicados, desenvolvidos no Laboratório de Ergonomia e Interfaces, do Departamento de Design da Faculdade de Arquitetura, Artes e Comunicação, da Universidade Estadual Paulista "Júlio de Mesquita Filho" - Campus Bauru. As atividades deste núcleo de pesquisa iniciaram-se na década de 1990, mas foram oficialmente iniciadas no ano de 2002, com a instalação de espaços e equipamentos próprios - para realização de estudos, investigações e experimentos que envolvessem o Design de produtos e sistemas, seus aspectos ergonômicos e de interface (interação). Os vários projetos apresentados e discutidos - e tantos outros com igual relevância, também desenvolvidos no LEI-UNESP - se complementa à publicação de inúmeros outros estudos científicos, à formação de pessoal especializado: Designers, Mestres e Doutores em Design, além da participação direta e indireta de colaboradores, estudantes, pesquisadores nacionais e internacionais.
\end{abstract}

PALAVRAS-CHAVE: Design, Design Ergonômico, Acessibilidade, Design Universal 